\title{
THE EFFECT OF LIGHT ON THE BUOYANCY OF THE CUTTLEFISH
}

\author{
By E. J. Denton and J. B. Gillin-Brown ${ }^{1}$ \\ The Plymouth Laboratory \\ (Plate I and Text-figs. I and 2)
}

By moving liquid in or out of the rigid cuttlebone and so changing the volume of the gas spaces which it contains, the cuttlefish, Sepia officinalis (L.), can make itself more or less dense than sea water (Denton \& Gilpin-Brown, I96I). The following experiments give an example of the use of this mechanism during the life of the animal.

The behaviour of well fed cuttlefish is greatly affected by light. When the light is bright they usually bury themselves in the gravel at the bottom of their tanks, whilst after twilight they come out of the gravel and swim around until dawn. Here we show that striking changes in buoyancy accompany changes in light intensity. The experiments were of two kinds; the first was designed to study the pattern of behaviour of cuttlefish in a normal day and night light cycle, the second to find out whether changes in behaviour with light intensity are associated with changes in buoyancy.

It is very difficult to provide adequate living room in the Plymouth Laboratory's experimental tanks for large adult Sepia. Most of the experiments described here were made on small cuttlefish, of less than $300 \mathrm{~g}$, caught in Plymouth Sound. Some confirmatory experiments were made on large Sepia kept in two large cages suspended in the Laboratory's sea-water reservoir.

\section{Methods BEHAVIOUR EXPERIMENT}

Thirteen cuttlefish, 5-I0 $\mathrm{cm}$ long, were placed under sea-water circulation in a tank $115 \times 65 \times 35 \mathrm{~cm}$ in September 1959. Shell gravel and stones were spread over the bottom of this tank to a depth of about $5 \mathrm{~cm}$, and a black cloth was placed over the only glass side so that natural light only came from overhead and the animals were little disturbed by passers-by. These cuttlefish were fed regularly on small prawns. They remained healthy, and grew in size, until this experiment was made some 7 weeks later.

A camera was set up so that all the tank was included within the $35 \mathrm{~mm}$ frame, and electronic-flash photographs were made at intervals during day and night. The flash was sufficiently powerful to overcome daylight during

\footnotetext{
${ }^{1}$ Present address: Department of Zoology, The University, Auckland, New Zealand.
} 
the day and of short enough duration to give little if any disturbance to the cuttlefish at night. Photographs such as those shown in Pl. I, were obtained, and these show how many cuttlefish were buried at different times of the day and night.

The illumination was natural diffused daylight, reflected into the top of the tank from the white walls of the laboratory. The fraction of daylight reaching the floor of the tank was found by comparing (with an Ilford SE I photometer) the luminance of a flashed white opal diffusing surface placed on the bottom of the tank with that for the same surface placed in shallow water under an open sky. It was found that the illumination on the floor of the tank was about $\frac{1}{100}$ th that outside the building. This is the fraction of daylight in the waveband $450-550 \mathrm{~m} \mu$ (i.e. that to which Sepia is probably most sensitive) penetrating to about $40 \mathrm{~m}$ in the sea off Plymouth (Poole \& Atkins, 1937; Jenkin, 1938). The cycles of intensity were therefore approximately those to which the cuttlefish would be exposed in their natural habitat. The variations in light intensity during the course of the experiment were measured (with the SE I photometer) on the white wall immediately above the tank so that the cuttlefish were disturbed as little as possible. One of the curves in Text-fig. I shows the variations of intensity with time, the light being approximately $\frac{1}{100}$ th that of the light outside the building.

\section{Results}

In Text-fig. I the number of cuttlefish not buried and the intensity of light have both been plotted against time. It is clear that at dusk, as the light intensity falls, cuttlefish come out of the gravelly bottom and swim about. This swimming phase lasts throughout the night until dawn when the cuttlefish again bury themselves in the gravel. Although the graph only indicates the numbers above the bottom and not their depth, occasional observations made during the night with a very weak red light always showed some cuttlefish swimming near the surface or in mid-water.

\section{Methods BUOYANCY EXPERIMENT}

For this experiment two cuttlefish of about 330 and $260 \mathrm{~g}$ were placed in a tank $(85 \times 40 \times 55 \mathrm{~cm})$ with gravel on the bottom in a dark room.

The weight of a cuttlefish in sea water was found by weighing it (on a torsion balance) under sea water in a watertight polystyrene box filled with sea water. It is quite easy to shepherd an animal into such a box and to make

\section{Explanation of Plate I}

A tank containing thirteen cuttlefish photographed by flash photography. The upper photograph was taken in the night and all thirteen cuttlefish are unburied. The lower photograph was taken in the daytime and all thirteen cuttlefish are buried. 


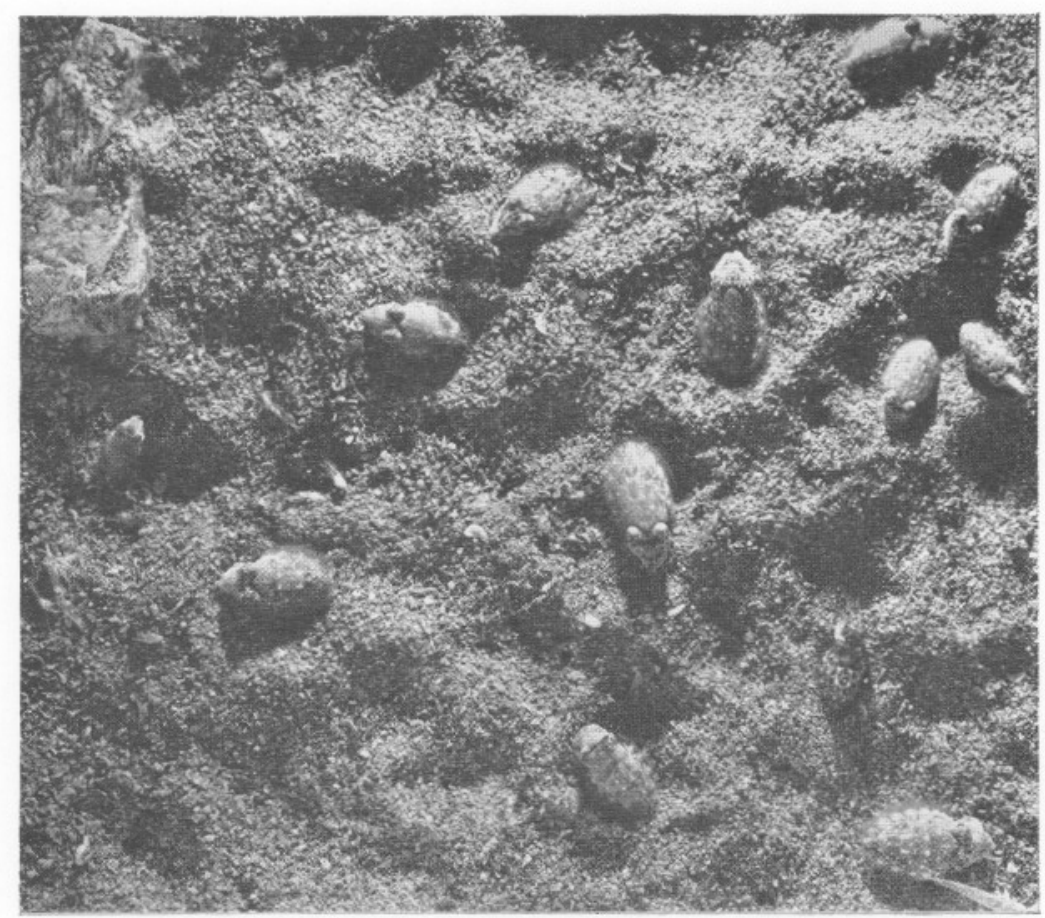

\section{Night}

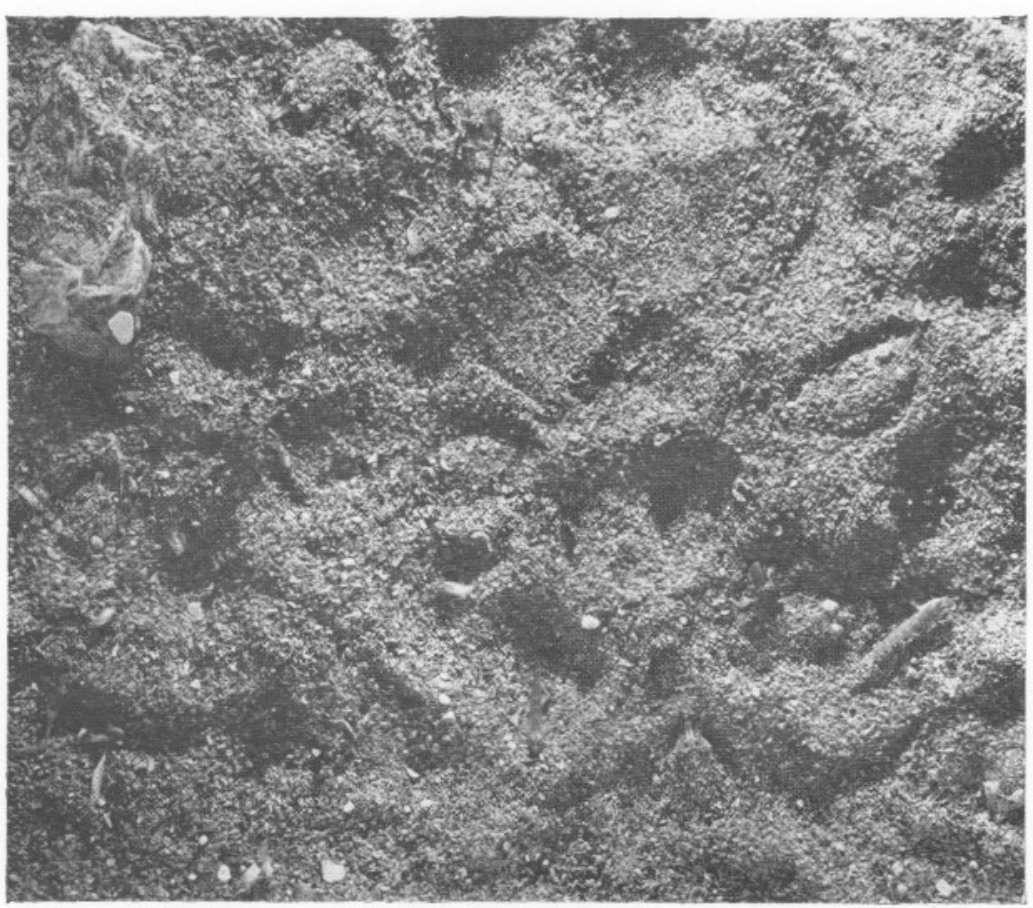

\section{Day}

(Facing p. 344) 
sure that no bubbles of gas or bits of gravel are present. If an animal weighs $-3 \mathrm{~g}$ in sea water then the weight of the box + animal + sea water will be $3 \mathrm{~g}$ less than the weight of the box filled with sea water only. A cuttlefish suffers no ill effects from repeated weighings of this kind, and a record of its changes in buoyancy with time can be made.

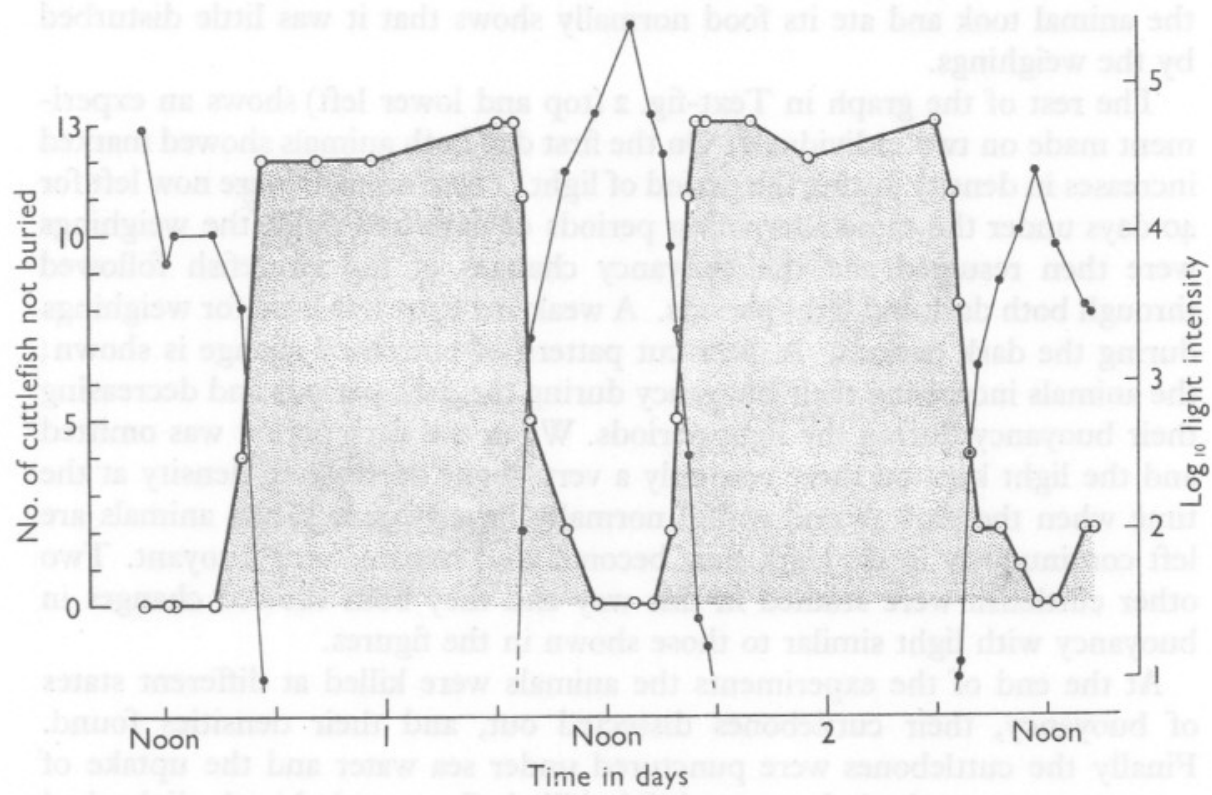

Text-fig. I. Sepia officinalis. Diurnal changes in the behaviour of the animals. $\bigcirc$, Number of animals not buried (total number of animals 13 ). - , Changes in natural light intensity on a logarithmic scale. The light corresponds in intensity roughly to that found in the sea off Plymouth at $40 \mathrm{~m}$ but it differs somewhat in its spectral composition.

At the end of an experiment the animal was killed, the mantle cavity cut open and examined for air bubbles, and the animal weighed directly in sea water. The figure obtained by this direct weighing always agreed with that calculated from the measurement made in the box just before death. Later the animal was dissected to see whether there were any stones in the gut.

An automatic time switch was set to put the light on at $10.00 \mathrm{~h}$ and off at $22.00 \mathrm{~h}$ every day. The light source was a I00 W tungsten pearl lamp suspended $65 \mathrm{~cm}$ above the floor of the tank.

\section{Results}

A pilot experiment on one animal is shown in the lower right-hand corner of Text-fig. 2. The animal had been kept overnight in the dark and measurements were started as soon as the light was turned on. At this time it was 
less dense than sea water, but its density increased fairly rapidly so that at the end of the day it was denser than sea water. At the time indicated by the arrow the cuttlefish fed on prawns. Prawns are denser than sea water and produced an immediate increase in the density of the cuttlefish. Apart from the temporarily added weight of the prawns, the cuttlefish continued to decrease its buoyancy at a smooth rate throughout the day. The fact that the animal took and ate its food normally shows that it was little disturbed by the weighings.

The rest of the graph in Text-fig. 2 (top and lower left) shows an experiment made on two individuals. On the first day both animals showed marked increases in density during the period of light. These animals were now left for 40 days under the same alternating periods of dark and light, the weighings were then resumed and the buoyancy changes of the cuttlefish followed through both dark and light periods. A weak red light was used for weighings during the dark periods. A clear-cut pattern of buoyancy change is shown; the animals increasing their buoyancy during the dark periods and decreasing their buoyancy during the light periods. When the dark period was omitted and the light kept on there was only a very slight decrease in density at the time when the dark period would normally have begun. When animals are left continuously in the dark they become, and remain, very buoyant. Two other cuttlefish were studied in this way and they both showed changes in buoyancy with light similar to those shown in the figures.

At the end of the experiments the animals were killed at different states of buoyancy, their cuttlebones dissected out, and their densities found. Finally the cuttlebones were punctured under sea water and the uptake of sea water measured. A dense cuttlefish, killed after a period in the light, had a cuttlebone of high density 0.65 which rose to 0.75 on puncturing under sea water. A second cuttlefish died when near neutral buoyancy and had a cuttlebone of density 0.62 , rising on puncturing to 0.74 . Two cuttlefish brought to low density by a period in the dark, had cuttlebones with the low densities of 0.54 and 0.55 , which rose to 0.75 and 0.78 respectively on puncturing under sea water. As found earlier (Denton \& Gilpin-Brown, I96I) no matter what the initial density of the cuttlebone the final density on puncturing is almost constant. This shows that the mass of gas within the cuttlebone remains almost constant when the cuttlebone density is changed.

Legend to Text-fig. 2

Text-fig. 2. The ordinate shows the weight of a cuttlefish in sea water (a negative weight means that the animal is less dense than sea water). The dark areas indicate times of darkness. Lower right-hand corner. Change in weight in sea water of a cuttlefish which had been kept for $\mathrm{I} 2 \mathrm{~h}$ in the dark and was then subjected to $\mathrm{I} 2 \mathrm{~h}$ light. At the time marked with an arrow the cuttlefish ate two prawns. Top, continued lower left. Change in weight of two cuttlefish. The upper curve is for an animal varying in weight around $330 \mathrm{~g}$, the lower curve for an animal varying around $260 \mathrm{~g}$. 


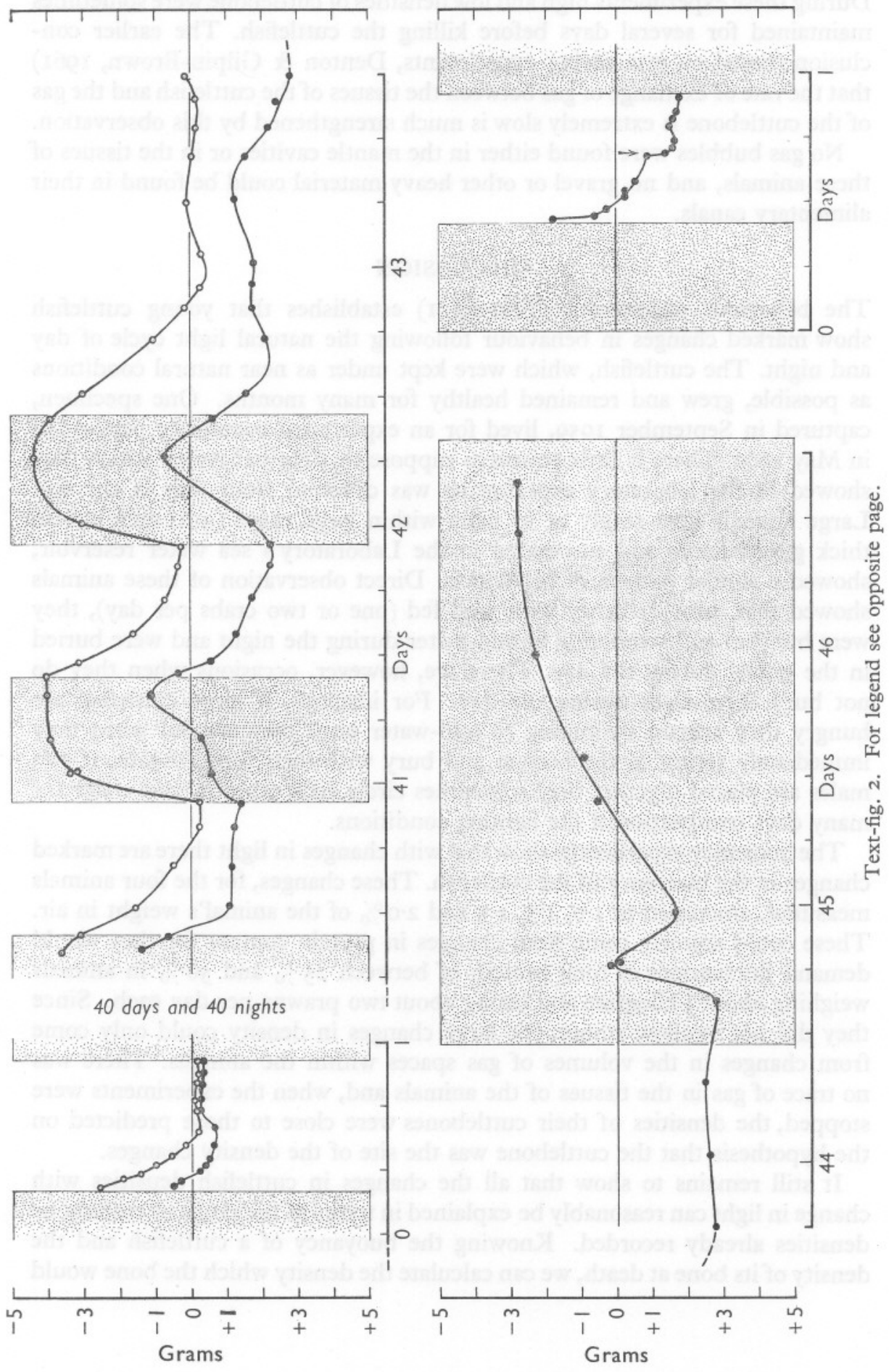


During these experiments high and low densities of cuttlebone were sometimes maintained for several days before killing the cuttlefish. The earlier conclusion (based on puncturing experiments, Denton \& Gilpin-Brown, I96I) that the rate of exchange of gas between the tissues of the cuttlefish and the gas of the cuttlebone is extremely slow is much strengthened by this observation.

No gas bubbles were found either in the mantle cavities or in the tissues of these animals, and no gravel or other heavy material could be found in their alimentary canals.

\section{DISCUSSION}

The behaviour experiment (Text-fig. I) establishes that young cuttlefish show marked changes in behaviour following the natural light cycle of day and night. The cuttlefish, which were kept under as near natural conditions as possible, grew and remained healthy for many months. One specimen, captured in September 1959, lived for an experiment eventually performed in May 1960. There is little reason to suppose that the behaviour which they showed in the laboratory experiments was different from that in the sea. Large animals kept singly or in pairs within large cages ( $4 \mathrm{ft}$. cube), with thick gravel floors and suspended in the Laboratory's sea water reservoir, showed a similar pattern of behaviour. Direct observation of these animals showed that, provided they were well fed (one or two crabs per day), they were buoyant and swimming in mid-water during the night and were buried in the gravel during the day. There are, however, occasions when they do not bury themselves during the day. For instance, if large cuttlefish are hungry they remain swimming in mid-water until they are fed when they immediately return to the bottom and bury with their food. Again, if two males are placed together they sometimes circle each other in mid-water for many days irrespective of the lighting conditions.

The buoyancy experiments show that with changes in light there are marked changes in the buoyancy of the cuttlefish. These changes, for the four animals measured, amounted to I.0, I.5, I.5 and $2 \cdot 0 \%$ of the animal's weight in air. These could scarcely come from changes in protein content for they would demand fluctuations of total protein of between $25 \%$ and $50 \%$ in animals weighing about $\frac{1}{3}$ kilogram and eating about two prawns per day each. Since they did not swallow stones, the large changes in density could only come from changes in the volumes of gas spaces within the animals. There was no trace of gas in the tissues of the animals and, when the experiments were stopped, the densities of their cuttlebones were close to those predicted on the hypothesis that the cuttlebone was the site of the density changes.

It still remains to show that all the changes in cuttlefish densities with change in light can reasonably be explained in terms of the range of cuttlebone densities already recorded. Knowing the buoyancy of a cuttlefish and the density of its bone at death, we can calculate the density which the bone would 
have had at other times during the experiment. The calculated values for cuttlebone densities when these four cuttlefish were at minimum, maximum, and neutral buoyancy are given in Table I. There they are compared with the maximum and minimum values found by Denton \& Gilpin-Brown (I96I) for a number of adult cuttlefish kept in the laboratory. The range given on these four animals, $0.77-0.48$, is somewhat greater than the range $0.7 \mathrm{I}-0.48$ found earlier. This is only to be expected because this experiment, with its long periods of light and dark, was designed to send the cuttlefish into abnormally high and low states of buoyancy. When kept in the dark for long periods cuttlefish become so buoyant that they are incapable of staying on the bottom and can only remain in mid-water with difficulty. Typically such a cuttlefish can swim head down to the bottom of the tank, but when it tries to level out in preparation for burying it at once starts to float upwards

TABLE 1

Calculated density of the cuttlebone when the cuttlefish was at

$\begin{array}{cccc}\text { Cuttlefish } & \begin{array}{c}\text { Minimum } \\ \text { buoyancy }\end{array} & \begin{array}{c}\text { Neutral } \\ \text { buoyancy }\end{array} & \begin{array}{c}\text { Maximum } \\ \text { buoyancy }\end{array} \\ \text { A } & 0.65 & 0.61 & 0.53 \\ \text { B } & 0.64 & 0.63 & 0.48 \\ \text { D } & 0.77 & 0.65 & 0.54 \\ \text { Range of densities already } & 0.69 & 0.67 & 0.54 \\ \text { recorded (Denton \& Gilpin- } & 0.71 & - & 0.48 \\ \text { Brown, I96r) } & & & \end{array}$

again. In the experiment of Text-fig. 2 the cuttlefish were subjected to total darkness for $\mathrm{I} 2 \mathrm{~h}$ and the low cuttlefish densities obtained during the dark periods are certainly lower than normal. In the sea since the optimum buoyancy for swimming is probably near neutral (i.e. zero weight in water) only a small change in buoyancy need occur between day and night.

The maximum rates of change in weight in sea water for one animal (Table I, B; Text-fig. 2, upper curve) were $\mathrm{I} \cdot 5$ and $\mathrm{I} \cdot 4 \mathrm{~g} / \mathrm{h}$ when getting lighter and 0.7 and $0.66 \mathrm{~g} / \mathrm{h}$ when getting heavier. This cuttlefish weighed $336 \mathrm{~g}$ in air and its cuttlebone had a volume of $30.4 \mathrm{ml}$., so that this animal could lose weight in sea water at a rate equal to $5 \mathrm{~g} / \mathrm{h} / \mathrm{roO} \mathrm{ml}$. of cuttlebone. Similarly, it gained weight in sea water at a rate equal to $2 \cdot 3 \mathrm{~g} / \mathrm{h} / \mathrm{IOO} \mathrm{ml}$. of cuttlebone. Such a rate of change would enable a cuttlefish to go from being slightly heavier (say $0.2 \%$ ) than sea water when buried in the bottom, to a neutral state for swimming in less than half an hour. A cuttlebone from which the siphuncular membrane has been removed and which is soaked in sea water gains weight at a maximum rate of about $5 \mathrm{~g} / \mathrm{h}$ for $100 \mathrm{ml}$. of cuttlebone (Denton \& Gilpin-Brown, 196I). This rate is more than twice that found in the intact animal, and it is therefore unnecessary to assume that 
any active process is used in pumping liquid into the cuttlebone when a cuttlefish makes itself denser. The cuttlefish must, of course, do active work when it extracts liquid from the cuttlebone to become less dense.

These experiments show then that the cuttlefish is able to change its density at quite rapid rates and almost certainly does so to help it lie at the bottom during the day and to keep it off the bottom during the night.

We wish to thank $\mathrm{Mr}$ A. C. Briggs for collecting young cuttlefish in exceptionally good condition and $\mathrm{Mr} \mathrm{F}$. J. Warren for the loan of his camera.

\section{SUMMARY}

The behaviour of well fed cuttlefish is strikingly affected by light. When the light is bright they usually bury themselves in the gravel at the bottom of their tanks, whilst after twilight they come out of the gravel and swim around until dawn.

Cuttlefish kept in complete darkness for one to two days usually become so buoyant that they are incapable of staying on the bottom and can only remain in mid-water with difficulty.

Animals kept in artificial light and dark showed changes in density which could amount to $2 \%$. These changes come from changes in the volume of the gas space within the cuttlebone.

The density of the cuttlefish is largely governed by light intensity and there is little indication of an inherent diurnal rhythm of density change.

The rate of uptake of liquid when the cuttlefish becomes denser is such that it is unnecessary to assume that any active process is used to pump liquid into the cuttlebone. The cuttlefish must, however, extract liquid actively from the cuttlebone to become less dense.

\section{REFERENCES}

Denton, E. J. \& Gilpin-Brown, J. B., I96I. The buoyancy of the cuttlefish. F. mar. biol. Ass. U.K., Vol. 4I, pp. 319-342.

JeNKIN, P. M., I938. Oxygen production by the diatom Coscinodiscus excentricus Ehr. in relation to submarine illumination in the English Channel. F. mar. biol. Ass. U.K., Vol. 22, pp. 30I-43.

Poole, H. H. \& Atkins, W. R. G., 1937. The penetration into the sea of light of various wavelengths as measured by emission of rectifier photoelectric cells. Proc. roy. Soc. B, Vol. 123, pp. I53-65. 